\title{
O artigo na toponimia galega: aspectos da estandarización*
}

\author{
Ana Isabel Boullón Agrelo \\ Universidade de Santiago de Compostela
}

\begin{abstract}
Resumo:
Neste traballo analízanse os problemas que presenta a estandarización dos topónimos con artigo: a súa presenza ou non na forma oficial, as contraccións coas preposición e o feito de algunhas formas presentaren un uso flutuante do artigo, debido a que o artigo moderno non procede do demostrativo latino que orixinou o artigo (ILLE, -A, -UD), senón da deglutinación dun $O$ - ou $A$ - iniciais que formaba parte orixinariamente da palabra a que hoxe anteceden. Establecerase a historia interna de cada voz, tendo en conta a etimoloxía e as documentacións antigas, confrontándoa cos criterios propostos pola Comisión de Toponimia. Ademais, atenderase á situación sociolingüística a que se viron expostos os topónimos así formados, no que toca á castelanización, desde o séc. XVI en diante, e as consecuencias que deste proceso aínda se derivan nos nosos días, especialmente no que toca ao tratamento da toponimia galega como exonimia desde o español.
\end{abstract}

\section{Palabras chave:}

Artigo determinado, topónimos, sociolingüística, etimoloxía.

\begin{abstract}
:
This study analyses the problems that arise in the standardization of toponyms with the article: the presence or not of it in the official form, contractions after prepositions and the way in which some forms present a fluctuating use of the article where the modern article has not evolved from the Latin demonstrative, which gave origin to the article (ILLE, -A, -UD) but from the division of an initial O- or A- that formed part originally of the word which they precede today. It will establish the internal history of each word by taking etymology and ancient documentation into account, and by comparing them with the criteria proposed by the Toponyms Commission. Furthermore, it will consider the sociolinguistic situation of these place names with regard to castilianization from 16th century onwards, and the consequences that are still in effect from this process in the present day, especially in the treatment of Galician place names as exonims in Spanish.
\end{abstract}

\section{Key words:}

The definite article, place-names, sociolinguistics, etymology.

* Este traballo enmárcase dentro do proxecto de investigación PRONORMA, para a recompilación, análise e normalización da toponimia das áreas meridionais de España, dirixido por $\mathrm{M}^{\mathrm{a}}$ Dolores Gordón Peral, na Universidade de Sevilla, subvencionado polo Ministerio de Ciencia e Innovación $\left(\mathrm{n}^{\circ}\right.$ de referencia FFI2009-10544). 


\section{A estandarización: situación actual e precedentes medievais}

Os topónimos con artigo son moi numerosos; un rápido cálculo dos lugares de Galicia que o conteñen ofrecen unha cifra próxima ao $48 \%$ do total: son 17.853 , correspondentes a 6.261 formas léxicas diferentes. A maior parte deles determinan substantivos procedentes do léxico común (A Agra, As Bouzas, A Braña, O Bugallal, O Codeso, Os Lamegos, A Laxe, O Louseiro, etc.), e, por tanto, algúns repítense moitas veces ${ }^{1}$. En menor proporción están presentes en formas hoxe opacas (O Grove, A Golada, A Baña, etc.). En ambos e dous casos, no que atinxe ao artigo, a Comisión de Toponimia ${ }^{2}$ considera o mesmo:

A comisión atense ó principio de que os artigos son parte integrante do topónimo, polo que se tivo especial coidado en verificar o seu uso na fala e oficializalo nos casos en que efectivamente se rexistrou e se documentou: A Coruña, A Laracha, A Lavacolla, A Pastoriza, As Somozas, O Carballiño, O Carril, O Porriño... (TopGal: 31).

Isto implica que os artigos figurarán no Nomenclátor de Galicia e que deberán expoñerse sempre nas denominacións oficiais, o que inclúe os carteis anunciadores das estradas, por poñer un exemplo moi visible. Ademais, para preservar o uso real nos textos escritos, o artigo contrae coas preposicións que o anteceden, igual que ocorre na lingua común: na Guarda, pola Coruña, como vén explicitado nas Normas ortográficas oficiais (RAG/ILG 2004: 86).

En portugués, idioma que nos podería servir de referencia á hora da estandarización, os artigos nos topónimos, aínda que se usen, non constan nos nomenclátores oficiais nin nos carteis informativos das estradas (cf. o caso do Porto). As gramáticas non adoitan ser moi explícitas a este respecto, e só indican que os topónimos formados por substantivos comúns conservan o artigo:

Aos nomes de cidades não se antepõe o artigo, a não ser que sejam compostos por nomes comuns. Assim: Coimbra, Madrid, Lisboa, mas o Porto, o Rio de Janeiro, a Figueira da Foz (Vázquez Cuesta / da Luz 1980: 464).

1 Algúns exemplos: hai 32 A Abelleira, 57 O Barral, 54 O Barreiro, 35 A Cabana, 75 O Carballal, 46 O Castelo, 215 O Castro, 117 O Cruceiro, 70 A Gándara, 323 O Outeiro, 73 A Pedreira, 122 A Pena, 127 O Souto, 132 O Vilar.

2 A Comisión de Toponimia é a institución encomendada pola Xunta de Galicia de fixar as formas estándares na toponimia (decreto 43/1884, DOG do 31.03.1984, modificado polo decreto 174/1998, do 5 de xuño, DOG do 22.06.1998). Os criterios que manexou están expostos de maneira sintética no prólogo do seu Nomenclátor de Galicia (2003), o primeiro feito realmente desde o galego, e algo máis pormenorizadamente no Informe sobre o Nomenclátor e o Proxecto Toponimia de Galicia (Xunta de Galicia, 2005), para onde remitirán desde agora as citas textuais, coa abreviatura TopGal. 
Alguns nomes das cidades que se formaram de substantivos comuns conservam o artigo: a Guarda, o Porto ... O mesmo ... com o nome de certas cidades estrangeiras: o Cairo, a Haia, o Havre (Cintra / Cunha 1984: 230).

são antecedidos de artigo os topónimos provenientes de substantivos comúns. ... usa-se a preposição contraida com esse artigo: ... no Porto, ao Porto, do Porto (Estrela / Pinto-Correia 1999: 54).

Os nomes das cidades só admiten artigo quando têm origem em nome comum: o Porto, a Figueira da Foz, a Feira, *a Lisboa, *o Setúbal (Mateus et alii 2003: 355).

En Internet atópase algo máis de información, que corrobora que a falta de prescrición leva consigo falta de uniformización no uso real:

quando o nome da localidade é simultaneamente um substantivo comum, este deverá ser precedido de um artigo definido, como acontece nos seguintes casos: «Vou ao Porto», «vivo na Guarda», «sou da Casa Branca». Algumas gramáticas, nomeadamente a de Cunha e Cintra (1985: 169) apresentam como regra geral a ausência de artigo definido antes dos nomes de localidades, vejase a título de exemplo os topónimos Lisboa, Águeda e Coimbra. Contudo, na realidade, não há regras fixas sobre a aplicação do artigo definido antes dos topónimos e é, sim, o uso que faz lei. Por essa razão, acontece, muitas das vezes, que são os naturais das localidades quem, na verdade, define se se deve ou não empregar o artigo com o topónimo. Assim sendo, pode-se dizer quer «estou na Fátima», como dizemos habitantes e naturais de lá, quer «estou em Fátima» como diz a maioria das pessoas que não vive nem nasceu nesta cidade portuguesa. (http://www.dosalgarves.com/revistas/N16/9rev16.pdf)

Así pois, hai diferenzas e semellanzas entre o galego e o portugués neste aspecto: en galego considérase o artigo como parte integrante do topónimo, e como tal debe grafarse con maiúscula e figurar nos carteis indicativos e no nomenclátor; en portugués gráfase con minúscula e non consta oficialmente; e aínda que se describe o seu uso, non se prescribe, admitindo en ocasións a súa ausencia. En ambos e dous se apunta a necesidade de contraer as preposicións cando o contexto o esixa.

Por outro lado, a realidade non é tan simple como parecen translucir os textos normativos portugueses, posto que non só hai topónimos con artigos cando proceden de substantivos comúns, senón que a casuística é moito máis complexa: amais destes, existen moitos topónimos con artigos con substantivos opacos, hoxe non pertencentes ao léxico común. 
O tratamento dos artigos nos nomenclátores anteriores ao Nomenclátor de Galicia non foi sistemático ${ }^{3}$, como en realidade tampouco o é a presenza do propio artigo nos topónimos, dado que, procedan ou non do léxico común, pode darse o caso de formas que se usan con artigo nun determinado lugar e sen artigo noutro: cf. Cabanela (7 lugares no Nomenclátor) / A Cabanela (8), Pazo (5) / O Pazo (154), Filgueira (15) / A Filgueira (7), Seixo (7) / O Seixo (49), etc. Así a situación, o único xeito de coñecer de maneira fiable a presenza do artigo é mediante entrevistas aos habitantes dos lugares, con preguntas indirectas en que a resposta incorpore unha preposición contracta co artigo do topónimo, do tipo: “¿Vostede que contesta cando lle preguntan onde vive?", para que na resposta figure: "Vivo na Illa" / "Vivo en Pedrafigueira" (vid. García Ares et alii 2002: 459). Tras ese traballo de campo, incorporouse ao nomenclátor unha alta porcentaxe de formas con artigo, algúns en formas transparentes e outros en topónimos actualmente "mudos", como O Sío, A Maramiga, A Rañoá, O Reconco, etc.

Hai unha cuestión que vén enguedellar o panorama un pouco máis: a interpretación como artigos das vogais $A$ - ou $O$ - en inicio de palabra que non eran tales etimoloxicamente. Da mesma maneira que os artigos se manteñen ou non no uso toponímico das palabras do léxico común, esta interpretación tampouco non foi sistemática, como se comproba en formas como Osebe $(<(*$ UILLA) EUSEBIUS, onde o $O$ - inicial non foi segmentado), ou en Agrela (1) / A Agrela (14) / A Grela (10) / Grela (1) (< AGRĚLlA, dim. de AGRA), onde atopamos todas as posibilidades. E aínda máis, parece que existiron casos de ida e volta, alomenos na escrita: o moderno topónimo Agrón, do concello de Ames, ao que se lle ten atribuído unha orixe prerromana (unha base *OKR- ŌNE: vid. Martínez Lema 2010: 314-5), nas máis antigas documentacións medievais, do TToxosoutos, a finais do XII e ata finais do XIII, atéstase como Ogrom, Ogron e Ogrone, aparentemente máis etimolóxicas, ou co antecedente directo da súa forma moderna: "Ssam Lourenço d'Agrõ" a.1390 LTenzasSantiago 28; non obstante, en épocas posteriores ese $a$ - foi interpretado como artigo, e consecuentemente modificado en $o$ porque un substantivo rematado en -ón asimílase ós substantivos masculinos: San Lorenço de Gron a.1507, San Lorenço d'Ogron a.1531, e Sant Lorenço do Gron, "Tiene mas su señoria en o Gron" a.1528 (CasaAltamira 220, 297). Actualmente, como está dito, a forma estándar é Agrón, quizais por restitución culta.

A todos estes casos cómprelles unha consideración semellante, pois son exactamente iguais desde o punto de vista sincrónico. Non se trata dunha cuestión meramente

3 E non facemos alusións aquí ás castelanizacións ou ás deformacións grotescas motivadas pola interpretación da secuencia inicial $L a$ - como se fose un artigo castelán, como *La Mamá en vez de Lamamá 'lama má', etc. 
gráfica, posto que a interpretación desas vogais iniciais como artigo é indubidable nas contraccións: "Vai no Grove" vs. "Vai en Osebe". Por tanto, aínda que etimoloxicamente non sexan tales, interprétanse como artigos actualmente, o que ocorre, en ocasións, desde a Idade Media. Os criterios aplicados pola Comisión dependeron do uso moderno, de maneira que se tiveron en conta as diversas situacións que se atopen na realidade (TopGal 32), e que exemplificaremos a seguir.

\subsection{Criterios da Comisión de Toponimia no uso do artigo}

1.1.1. Respéctase a deglutinación se está consolidada na fala e na tradición escrita e o termo toponímico non pertence ao léxico común.

1.1.1.1. Na maioría dos casos trátase de formas con deglutinación do artigo a partir de secuencias $A$ - ou $O$ - iniciais (en menor medida, $A s^{-}, O s_{-}$). Cando se documenta nos textos medievais, adoita pasar que nos textos altomedievais, en latín, apareza a forma máis etimolóxica, e na Baixa Idade Media xa se interpretara o artigo (incluímos unha lista non exhaustiva, pero si representativa).

- A Baña < med. Avania ("in terra de Auania" a.1153 TToxosoutos 503), coa terminación - nj- frecuente en hidrónimos e topónimos de orixe prerromana (Moralejo Álvarez 2008: 320, 336).

- A Garea (Ames-C), med. Dagarea (a.1456, 1528), Dagarii (1205) < (villa) Dacaredi, do nome de posesor de orixe xermánica Dacaredus / Dagaredus (HGNB 63.6). Aquí produciuse unha dobre deglutinación: primeiro interpretouse unha contracción vocálica a partir da preposición de, e despois o artigo (Martínez Lema 2010: 289).

- A Maía < med. Amaea (desde o a.854 SAMI 9, passim), Amaheae (a.1110 SAMI 77-78) Amaia (a.1149 TToxosoutos 302), Amaya (a.1255 TToxosoutos 386), Ameyia (a.1117 TToxosoutos 310), nomeada xa na Divisio Theodomiri como unha das demarcacións da sé iriense (ca. a.569), formada por unha raíz hidronímica indoeuropea *am- 'canle, leito, co suf. -ia (Bascuas 2002: 207-209). A deglutinación rexístrase desde o séc. XIII: “ena Meya” (a.1289 TToxosoutos 699).

- As Anzas (Ribadeo-Lu) < med. Alesantia (a. 775 DipAstur 66-68), hidrónimo formado coa raíz *el 'fluír', con alongamento $-s$ e sufixo $n t$; trala perda do -1-, interpretouse a parte inicial coma un artigo, e engadíuselle o $-\mathrm{s}$ final para que concordase (Bascuas 2002: 260, 287-288). 
- As Maus < med. Asmanos, xentilicio procedente de Asma, formado a partir dunha raíz hidronímica indoeuropea *aps, co sufixo - ma e mailo sufixo-ANUs (Bascuas 202: 177-9). A deglutinación do artigo atéstase xa no séc. XIII: "Petro Roderici das Maus" a.1241 CDOseira 449.

- O Baño (Mugardos-C) < med. Ouana (a.1257 Doc-1260), seguramente en relación con $A$ Baña (vid.). Neste caso houbo ademais un cambio xenérico: ao interpretarse como artigo o $o$ - inicial, acomodouse ao masculino a terminación orixinaria en $-a$.

- O Eixo (Santiago) < med. Olegio, Oegio, Oeyo, Eio, Eyo, Eo (a.1237 e ss. DocUnivSantiago passim; a forma máis latinizada (Olegio), desde a.1087 (TColoradoSantiago 223-226). Para Bascuas (2002: 297-298) está en relación coa raíz *el- 'fluír' e o sufixo -io, de orixinario valor hidronímico. O proceso de deglutinación do artigo estaba consumado xa polo menos no séc. XIV, a xulgar polas atestacións: "ennas uillas do Eyo" a.1344 DocUnivSantiago 190.

- O Incio < med. Onitio, desde o séc. IX (a.854 TSamos 238); ten un sufixo -itio moi frecuente en formacións prerromanas (Bascuas 2002: 48).

- O Ivedo (Castro Caldelas-Ou, Quiroga-Lu), med. Oliuetu < lat. OLIVEtu, der. colectivo de oliva (Navaza 2006: 381), con posible deglutinación do artigo desde o séc. XIII: "Fernan Eanes d'Oyuedo" a.1286 CDSClodioRibeiro 402.

- O Mao (río) < med. Humano, Omano, Homano (a.1103 TSamos 421). Formado polo tema hidronímico *um e o suf. $-n$, frecuente na hidronimia de tipo indoeuropeo (Bascuas 2002: 232).

- O Milladoiro (Ames-Co) < lat. humiLiatoriu (Moralejo Lasso 1977: 18); alí había un dos marcos que indicaban a acoutación dos $60 \mathrm{~km}^{2}$ que constituíron o primeiro xiro de Santiago, que ata o ano 1000 aparecían designados como miliarios:

Con el paso del tiempo y como una consecuencia más de la intensa afluencia de peregrinos por estos caminos terrestres, la emoción intensa de quienes pisaban por primera vez territorio compostelano al entrar en el suburbio o término, fue haciendo de estos puntos lugares de oración y agradecimiento por la feliz culminación del trayecto. Sobre cada miliario nació un humilliatorium, de tal manera que el espacio suburbano que rodeaba Compostela empezó a ser fácilmente definido con la expresión de humilliatorio en humilliatorio (López Alsina 1988: 134-135).

Outro topónimo coa mesma orixe conserva restos da vogal inicial: O Amilladoiro (Sobrado, Cesuras), forma que tamén debeu ter o topónimo de Ames, a xulgar 
por documentacións do séc. XVI onde aparece como Amilladoiro a.1509-1513 AHUS.

- Os Riós $(\mathrm{Ou})$. Este é un caso un tanto especial, porque na fala pronúnciase Orriós, pero cun tratamento fonético da primeira vogal semellante á dun artigo singular, e de aí a secuencia “estou n’Orriós”, por exemplo. Hai dúas posibles explicacións etimolóxicas para este topónimo: ben do lat. HORREOLOS, dim. de HORREUM 'tulla, celeiro, despensa', segundo parece indicar a grafía medieval Orriolos (a.1029 TCelanova 62); ou ben "pudiera proceder de *riviolos «arroyos, riachuelos»" (Moralejo Lasso 1977: 314), segundo hipótese apoiada tamén pola grafía medieval ILLOS RIUOLUS (vid. Méndez 2002: 508). En calquera caso, e tendo en conta que sempre se trata dun substantivo plural, a Comisión quixo respectar a pronuncia moderna mediante un artigo en plural que permite manter a contracción coas preposicións; ademais, dado que o encontro das dúas consoantes /sr/ se resolve na fala como unha vibrante múltiple, é posible tamén reflectir o fonema/r/ que se pronuncia realmente. Dos problemas que en canto á estandarización presenta este topónimo dá fe tamén o feito de que chegou a ser incluso malinterpretado como Os Ríos (vid. Rivas Quintas 2007: 479).

- O Xurés (cadea montañosa flanqueada polo río Salas, o Limia e o Cávado en Portugal) < med. Ugeres, Ogeres, Augeres, Ageres (TCelanova, desde a.1024, passim); as grafías con $A$ - son o resultado da aglutinación coa preposición latina $a(d)$ co topónimo. Ten unha raíz hidronímica que remonta á raíz indoeuropea *wegw - 'húmido, mollar' (Bascuas 2002:238-240).

- O Xuriz (Guntín-Lu) < (VILLA) OsORICI, topónimo de posesor de orixe xermánica (HGNB 205.9).

1.1.1.2. Están nun caso semellante aquelas secuencias cunha forma toponímica opaca cun artigo que non procede da deglutinación da palabra léxica que o forma. Desde o punto de vista da estandarización o seu tratamento é parello aos anteriores. O único que os diferencia é que se descoñece a razón etimolóxica de levaren artigo determinado.

- A Lavacolla (Santiago-Co) / Lavacolla (Outes-Co). Atestacións medievais: "Mayor Domingez de Lavacolla" a.1332 DocUnivSantiago 124. Os estudosos da etimoloxía véñenlle atribuíndo a orixe a partir “de LAVA COLEA 'lava testículos', nombre a la vez de la aldea y de su arroyo, que parece aludir a abluciones lustrales y se repite en el ayuntamiento de Entines en la misma provincia y casi en el portugués Lavacolhos (Fundão, Castello Branco)" (Moralejo Lasso 1977: 318, n.85, a partir de Pensado 1965). É unha atribución que xa fixeran os autores 
do Códice Calixtino ao designaren o lugar coa forma Lavamentula, o que sería, segundo Pensado, unha latinización eufemística. Pero precisamente a aparición do artigo fai pensar noutra orixe, en relación cunha raíz laba- alteración da raíz indoeuropea prerromana nava, presente en Navia, Navallo, etc., como suxire Rivas (1982: 132).

- A Laracha (Co), de orixe prerromana, relacionada con outros topónimos como Laraño, Laranga, da raíz *pelH" - 'plano, ancho' (Bascuas 2002: 41).

- A Coruña (nome do concello da provincia homónima e mais dun lugar no concello do Val do Dubra-Co). Curiosamente, non hai ningún estudo recente que se detivera na etimoloxía, cando desde hai séculos se lle veñen atribuíndo as máis diversas orixes $^{4}$. O feito é que hai algunhas circunstancias anómalas. Por unha parte, nos textos máis antigos o territorio aparece citado como Brigantia ou Faro (pola construción actualmente chamada Faro de Hércules), e só comeza a citarse $A$ Crunia a principios do séc. XII ${ }^{5}$. Para explicar esa datación tardía nas fontes documentais, tense falado, por unha banda, dunha repoboación procedente da vila de Burgos Coruña del Conde; por outra banda, Vaamonde Lores (apud Barreiro Fernández 1986: 95) especulaba con que fose o nome dun antigo barrio da primitiva cidade e que a repoboación se fixo sobre el, "in loco qui dicitur Crunia" (a.1208), expresión que fai explícito o feito de o nome xa existir previamente. As dúas hipóteses carecen de probas, pero a segunda parece máis plausible. Por outro lado, a partir dunha orixe cun grupo KL- agardaríase unha palatalización. Moralejo Lasso (1977: 276) pensa nunha posible influencia medieval culta na primeira sílaba, e Antón Santamarina, en comunicación oral, apunta cara á importancia que podería ter o contorno fonético: a existencia dunha palatal na segunda sílaba puido impedir a palatalización da primeira, nunha especie de disimilación preventiva. En definitiva, no que si parece haber consenso ultimamente é en que a orixe é prerromana; a existencia do artigo podería indicar que o topónimo tivese en principio unha significación transparente (Moralejo Lasso 1977: 276).

En textos escritos en latín a variante maioritaria era Crunia (ou as formas flexionadas Cruniam, Crunie e o xentilicio cruniensis), con 78 ocorrencias no CODOLGA; as formas máis romanceadas están en textos datados en épocas de escritura romance: 2 Cruna (a.1262 CDGH 265-269), 1 Crunna, 1 Curunia. A

4 Desde Afonso X, que o atribúe ao nome persoal da primeira muller alí moradora (vid. Moralejo Álvarez 2008: 62-67), ata as teorías decimonónicas que defendían a procedencia a partir de diversas formas latinas como COlumna, CORONA, COLONIA, ou da francesa Cluny (pola influencia da orde cisterciense): véxase Martínez Salazar (1948) e Barreiro Fernández (1986: 92-5).

5 As aparicións de Clunia nas fontes romanas refírense á cidade burgalesa Coruña del Conde. 
forma con CL-, Clunia, só aparece dúas veces. En canto ao artigo, aparece sempre sen el, non sendo en dous casos de formas romances e datacións tardomedieval, onde debe haber influxo do castelán, como se ve polas características do documento. Incluímos a seguir os exemplos das formas máis escasas e unha selecta das maioritarias.

“concilio et alcallibus de Crunia" a.1188-1230 TBSantiago 584-586.

"construo populationem in loco qui dicitur Crunia, apud turrim de Faro, et propter hoc ecclesia Sancti Iacobi” a.1208 TASantiago 341-343.

“concilio de Curunia" a.1208-1210 González 1944: 321.

"villam de Clunia" ca.1160 García Conde (1976).

"facta carta apud villam de Clunia" a.1228 González 1944: 665.

"Alfonsus Roderici de la Cruna, canonicus compostellanus" a.1483 DocUnivSantiago 454 = "Alfonsum Roderici de la Crunna, canonicum compostellanum" a.1484 DocUnivSantiago 457. Nos dous casos é un documento asinado polo papa Sixto IV, onde se lle outorga ao bispo de Ciudad Rodrigo e a Nicolás de Salmerón, arcediago de Huete (Cuenca) unha bula en favor de Afonso Rodríguez da Cruña; no segundo documento Nicolao de Salmerón executa o nomeamento.

En textos escritos en galego (para os cales re recorre ao TMILG) a situación é a contraria: das 135 veces que aparece nas súas variantes Cruña, Crunna (maioritarias) e Crunia, Crugna, Cruna, e as 6 de Curuña, Corunia, Coruna, Coruña, só en catro ocasións aparece sen artigo. Por outro lado, as formas con vogal epentética (Curuña, Corunia, Coruña) comezan a aparecer no séc. XIV e danse sobre todo no XV. A forma primeira, Cruña, continuou sendo a popular ata os nosos días.

"foy Lourenzo Eanes polo uino aa Crunia" a.1242-1252 DocXIII-XVI 9.

"o Concello da Crunna", "Johan Marinno, notario jurado del rey enna Crunna" a.1255 DocHCoruña 494.

"Martin Perez, notario publico del Rey na Cruña" a.1282 DocXIII-XVI 88.

"Rodrigo Mit da Curuña" a.1339 CDGH 372.

"cartas que enviaron aa Cruña" a.1419 LCSantiago 178.

"na ciudade da Coruña" a.1465 DocHCoruña 519.

"da dita çibdade a Crunna" a.1448 DocHCoruña 638 


\author{
"Pedro Perez de Crugna" a.1262 CDMaia 42. \\ "Martin Perez notario de Crunna" a.1282 DocHCoruña 500. \\ "Afonso Perez de Regueira, retor da igrexa de Santiago de Cruna" a.1294 \\ DocHCoruña 511. \\ "Iohan Gasco morador en Corunia" a.1399 CDTui 457.
}

Na documentación en castelán pode aparecer o artigo en castelán, como se ve neste texto emanado polo rei:

Don Johan por la graçia de Dios, rey de Castilla, de Leon, de Toledo, de Gallizia, de Sevilla, de Cordova, de Murcia, de Jahen, del Algarbe, de Algezira, et señor de Vizcaya et de Molina, a los Consejos, e corregidores e jueses et alcalles et merinos et regidores et jurados et justiçias et otros ofiçiales qualesquier de la çibdat de Santiago, con las villas de la Curuña et Betanços (a.1418 LCSantiago 279).

Hoxe en día o uso en galego é xeral con artigo. Das documentacións medievais inferimos que a súa representación escrita debeu variar: aínda que non se representaba nos textos latinos (o cal non é de estrañar, pois o latín carecía deste tipo de palabras), tiña que existir xa, pois non é comprensible que apareza ex novo e de forma case xeral acompañando a un topónimo opaco que non tiña correlato no léxico común. Por outra parte, nos textos escritos en romance o xeral era aparecer sempre o artigo, con moi poucas excepcións.

1.1.2. Se a forma deglutinada non está consolidada (o que significa que na fala se pode testemuñar tanto co artigo independente coma coa inicial formando parte da palabra), mantense a etimolóxica:

- Oxén $\left(\mathrm{Co}_{2}, \mathrm{Ou}_{3}\right)<$ (UILla) EugeniI. Aquí, ademais, deuse unha monotongación en posición tónica que aínda non se consumara na Idade Media: "Gundisalvus Martini d'Ougen" a.1272 CDOseira 963.

1.1.3. A Comisión aplicou criterios diverxentes para formas iguais en función do peso da tradición escrita ou da interpretación desa secuencia na fala (como artigo ou como parte integrante do topónimo).

- Agolada (Po) / A Golada (Becerreá-Lu, Nigrán-Po) / A Agolada (Barreiros-Lu) < lat. AQUA LATA 'auga levada' (Moralejo Lasso 1977: 315-6). Danse aquí as tres posibilidades, incluída a xeración dun artigo a partir da forma plena. No caso do 
topónimo que hoxe constitúe concello, a información máis antiga de que se ten constancia é do XVI, citada como "San Lourenzo da Agualada" (a.1509 AHUS), moi próxima á etimolóxica e xa con artigo (e tamén sen el: "en Agualada a.1541 AHUS), e despois, no XVIII, no catastro de Ensenada, onde se di que a parroquia de Ferreiroa "tiene una taverna que se llama Agolada"; o proceso de deglutinación está hoxe en día en proceso e adoita utilizarse na fala.

- Agrela (Alfoz-Lu) / A Agrela (13 lugares) / A Grela (12 lugares) / Grela (MeisPo), med. "Lourenzo Ares d'Agrela" a.1278 CDOseira 1068, "Laurencius Arie da Grela" a.1274 CDOseira 1028, "en a ribeira da Grela" a.1399 DocHCoruña 5887.

- O Grove (Po) / Ogrobe (Mondoñedo-L, Pontedeume-C). Danse as primeiras atestacións medievais de cada forma referida á vila pontevedresa: "ecclesiam Sancti Uincentii in insula Ocobre" a.899 TASantiago, "sanctum Vicentium de Ogobre" a.912 SAMI, "sanctum Vincentium de Ogrove" a.1115 SAMI, "Pedro Perez do Villar do Groue" a.1322 CDMaia 231, "Juan Garçia do Grove" a.1444 LCPontevedra 179. A documentación amosa a deglutinación do artigo desde o séc. XIV. Este é dos moitos topónimos galegos que portan a terminación -bre, procedente dun tema briga, de raíz céltica, cun significado referente á un asentamento humano situado nunha elevación do terreo ${ }^{8}$. A primeira parte do topónimo podería ser un derivado da raíz indoeuropea $* h_{2} e k$ ' 'punta, esquina', da que se documentan nas distintas linguas indoeuropeas formas en $a k$ - e en $o k$ - (o que sería este caso); de maneira que o seu significado, combinando ambas e dúas raíces, sería 'monte do pico, monte agudo' (Búa 2007: 398, n.25).

- O Obre (Santo André -Paderne-Co) / Obre (Santa Mariña -Noia-Co). Só atopamos atestacións medievais desta última: "Santa Marina de Ovre" ou "Santa Maria de Ouvre" a.1337 CDBelvís 410. Outros topónimos Oure corresponden ao actual top. Ombre (Santa María -Pontedeume-Co), sen que a nasalidade estea explícita: así en "Sancta Maria do_Oure" a.1252-55 Doc-1260 266, que se identifica co máis antigo "Sancta Maria de Anovre" a.1167 TCaaveiro 235 e co máis recente "Onvre" a.1435 DocHCoruña 615. Coma o topónimo anterior, pertence á serie de formas prerromanas coa terminación - bre (para esta forma, véxase Moralejo Álvarez [2003] 2008: 176).

6 Información que lle agradezo a Luz Méndez.

7 Téñase en conta que a secuencia "dagrela" nos documentos medievais pode ser interpretada como d'Agrela ou da Grela segundo o criterio dos editores. O único que podemos constatar a partir destas edicións é que se producira unha elisión da vogal da preposición por fonética sintáctica.

8 Da moi abundante bibliografía sobre este tema salientamos Moralejo Lasso ([1952] 1977: 49-83), a actualización de Búa / Lois (1994-1995), e a reconsideración do primeiro destes dous autores sobre a etimoloxía das formas en -bre feita en Búa (2006: 389-390). 
- Porto do Son-Co / O Son (Cee-Co) / Son de Abaixo, Son de Arriba (Santiago -Santiago) / Ozón (San Martiño - Muxía-Co) / Dozón-Po (Santa María) ${ }^{9}$. Estes topónimos son de orixe semellante; a partir das formas medievais (Doçon, Deçon), interprétase que na primeira parte da palabra hai unha contracción coa preposición, e deglutínase esta (Ozón); ou ben considérase a primeira parte da palabra como unha contracción da preposición co artigo masculino; e daquela segméntase como Son; a forma que se mantén máis próxima ao étimo é Dozón (med. Deçon). As formas modernas con $s$ reflicten a evolución das sibilantes nas áreas respectivas. Velaquí algunhas atestacións antigas:

Porto do Son: “Antonia Vázquez Dozón” a.1558 AHUS, Doçon a. 1603, a.1696, Docon a. 1616, a.1628 Cartografia de Galicia (2000: 120, 139, 125, 122 , respectivamente).

Ozón-Muxía: "Sancti Martini de Ocon" a.1219 TToxosoutos 93, "Sanctum Martinum de Ozon" a.1220 TToxosoutos 102, "de Sam Martino d'Oçon" a.1334 TToxosoutos 702 .

O Son-Santiago: "en friigesia de Santiago de Doçon" a.1348 CDGH 304.

Dozón-Po: "Laurencius Martini iuratus notarius de Deçon" a.1264 CDOseira 872, e posiblemente "Terra de Deçon" a.1274 CDOseira (territorio situado no actual concello de Lalín), "terra de Orzellon et de Deçon" a.1411 CDSClodioRibeiro.

A orixe sería en última instancia para a forma Ozón un tema hidronímico *Upsco sufixo $-n$, segundo Bascuas (2002: 204), se ben Martínez Lema (2010: 312318), dadas as dificultades fonéticas que presentan a sibilante resultante, prefire partir da raíz indoeuropea $a k$-/ok- 'cortante, anguloso, aguzado', 'pedra', por medio duns étimos *OK-Ī-ŌNE (para Ozón) e DET-Ī-ŌNE (para o medieval Deçon, emparentado co hidrónimo Deza).

- O Saviñao-Lu / Saviñao (Meira-Lu). De Sabinianus, topónimo de posesor de Sabinius. Na Idade Media, as documentacións referidas ao concello lucense non reflicten o uso do artigo: "en terra de Sauinnao" a.1392 CDPombeiro 111, uso do que se descoñece a motivación.

1.1.4. Se non se poden recoñecer as aglutinacións ou deglutinacións, a Comisión atívose á tradición escrita; desa maneira poden aparecer aparentes dobretes, como Lugar da Riba / Lugar de Arriba.

9 Son en Navia de Suarna ten que ter outra orixe, porque aquí as grafías con $S$ - non se poden explicar por seseo. Podería ser un topónimo de posesor a partir do xentilicio lat. Son(n)ius (Solin / Salomies 1988: 425). 


\section{A representación na escrita da toponimia galega a partir do séc. XVI}

Evidentemente, non podemos afastar os topónimos con artigo do ocorrido coa toponimia galega no seu conxunto. Como é ben sabido, a partir do séc. XVI a lingua galega desapareceu dos textos escritos e, como consecuencia directa para a onomástica, procedeuse a unha case sistemática tradución (ou adaptación) para o castelán. Antón Santamarina (1988: 89) expón exemplos medievais de traducións e adaptacións, "tan antigos coma os propios documentos medievais (finais do XII e comezos do XIII)". Hai que ter en conta que o procedemento para adaptar topónimos procedentes doutras linguas foi variando no paso do tempo. Na Idade Media, o máis habitual era a naturalización, que, en Galicia, se daba sobre todo cos documentos producidos na chancelaría real, como vimos nalgún exemplo do capítulo anterior (páxina 20), e como comprobamos na nosa propia tradición literaria. Así, na tradución galega da Crónica Xeral e a Crónica de Castela hai topónimos como Badallouço, Cataloña, Conca, Talaveyra, Outer de Selas (Tordesillas) ou Valedolide (Lorenzo 1975 I: 907-993).

Pero o que ocorreu despois do XVI foi algo distinto: supuxo en boa medida a deformación da toponimia galega nos textos escritos. A partir dese momento comezaron a aparecer traducións máis ou menos sistemáticas que non tiña realidade máis ca nos papeis que termaban delas. Desa maneira, atopamos formas hoxe sorprendentes coma as seguintes:

1607: Junio (Xuño), Yobre (Xobre, na Pobra do Caramiñal) Carrera, Palmera, Olbera/Olibeira (Olveira, en Ribeira), Buero (Boiro), Liria (Lira) [Jerónimo del Hoyo, natural de Aguila Fuente, da provincia de Segovia, visitador da diocese de Santiago].

1759: Olleros (Oleiros), Sejo (Seixo), Juanceda (Xanceda), Jaguaza (Xagoaza), Jacebanes (Xacebáns) [Vecindario de Ensenada].

Certamente, a existencia destas formas, que non tiveron reflexo na realidade oral, non pode servir de xustificación para dar por boas unhas variantes que só tiveron existencia escrita. Pero tamén son un indicio claro de cal era a política lingüística da administración castelá coa toponimia galega naquelas épocas, que tivo unha importancia decisiva para a elaboración dos nomenclátores ${ }^{10}$ e a cartografía: así, os mapas da época moderna reflicten a nosa toponimia con graves deficiencias.

10 Como os dicionarios xeográficos e estatísticos de Miñano (1826-1829) e pouco máis tarde Madoz (1845-1850). Da importancia e influencia deste último dá fe o feito de que aínda a finais do séc. XX se seguía reeditando. 
Os topónimos adoitaban estar grafados con diferentes deformacións segundo fose a lingua en que estivesen escritos ou a tradición cartográfica que seguisen, pero decote con interferencias do castelán. Vese moi claramente nas cartas náuticas, que adoitaban ser publicadas por países con tradición marítima (como Holanda, Francia, Italia...) e mais nos mapas antigos. Velaquí algúns exemplos, tirados todos eles da Cartografia de Galicia (2000) ${ }^{11}$ e dispostos por orde cronolóxica:

Puente Vedra, Portonueve, Corcobaiona (Corcubión), Rondello (Redondela), Feroles (Ferrol), Coruna, Viveros, Riba Deos. Carta náutica de 1583: Orae Maritimae Gallaeciae. Waghenaer, pp. 26-8.

Vacolla, Signeiro (Sigüeiro), A Guarda, Baiona, Mellid, Rianfo, Touriuan, Mongia (Muxía), Coruña, Ferol, Biveiro, Puertomarin. En 1595, Galitia / Galizia hisp., p. 118.

R. Lezaro (Ézaro), Corcalion, Namancos, Corribedo, Villa nueva Daroça, san Xenxo, Mongia, Coruna, P. de le Desma (Ponte Ledesma), Orol, Vivero, Fuen sagrada. Gallaecia Regnum (Atlas de Mercator), a.1611, p. 127.

Conbados, Grobe Ins., Villa Ioan, Aroca Ysla, Puebla del Dean, Corcalion, Mongia, Corunna, Vivero, S. Cibrian. Gallicia, Legio et Asturias de Oviedo (Atlas Minor Gerardi Mercatori), a.1628, p. 122.

P Nuovo, Villa Nuova, Cambodo, Corcobaiona. Carta náutica de 1646-7: Carta particolare chi comincia con il capo Mogera in Portogallo è finisce con el capo di Coriano in Ispagna. Antonio Francesco Lucini, p. 34.

La Corogne, Mouros (Muros), Pontesdeme, Ferol, Vivero. Carte des costes septentrionales d'Espagne depuis Fontarabia jusqu'a Bayonne en Gallice, a.1693, p. 54.

Curuelle (Corrubedo), Courbion, Cabo de Toriana, Cabo Vellana o di Bellen (Cabo Vilán), La Corugna/Corunna, Puente d'Eume/Pontedesme, Arres, Ferol, Sidere / Cedeyra. Il Regno de Galicia, descritto da Giacomo Cantelli da Vignola, a.1696, p. 139.

Mouros (Muros), Cap de Courovelle (Corrubedo), Carta da costa de Galicia entre Cabo Vilán e Oia, ca. 1700, de Les costes de France e d'Espagne, p. 59.

Cartes des ports de Ferolle, et la Corogne, et des Ances de Pontesdeme, et Sada, s.XVIII 1ª/2, p. 61.

Courouvelle (Corrubedo), Mouros (Muros), Camerinos (Camariñas), Mellid, la Corogne, Signeyro (Sigüeiro), Fuen de Sagrada, Godomar. Royaume de Galice, province d'Espagne, N. De Fer, Atlas Curieux..., a,1700. p. 142.

11 Indicamos entre parénteses as equivalencias non doadamente recoñecibles. Máis casos do tratamento da toponimia galega na cartografía desde o a.1424, limitados á toponimia da Mariña lucense, en Insua (2010: 148). 
Corouvelle (Corrubedo), Corcaleon, Mengia (Muxía). Li regni di Galizia, Asturies, Leon... Atlante novissimo. Venezia, a.1779, p. 161.

Adoitan adaptarse aos idiomas respectivos as formas léxicas susceptibles de selo: PNuovo, Villa Nuova (nunha carta italiana), la Corogne (nunha francesa), con tendencia a seguir as castelanizadas, se ben os topónimos escuros defórmanse variadamente: cf. as distintas variantes de Corcubión (Corcobaiona, Corcalion, Corcaleon) ou de Corrubedo (Courovelle, Corribedo, Curuelle, Courouvelle, Corouvelle). E o tratamento do artigo é anárquico: pode omitirse (Coruna / Corunna, Grobe), naturalizarse (la Corogne, la Corugna) ou mesmo interpretarse como artigo castelán a secuencia Lacon que empeza o topónimo e posteriormente omitirse (Vacolla).

\section{Os topónimos galegos como exónimos: a RAE e a Wikipedia}

Esta tradición de deformación toponímica non fixo máis que acentuarse durante o franquismo, e foi a directa responsable de certas actitudes actuais de menosprezo con respecto aos topónimos orixinais. Ben se sabe que na Lei de normalización lingüística de Galicia disponse que a única forma oficial dos topónimos de Galicia será a galega ${ }^{12}$. Pese a iso, con aparente neutralidade, as últimas publicacións da Real Academia Española (2010) continúan cos usos escritos fortalecidos durante a ditadura, o que contrasta coa comprensión que aducen ante variantes da propia lingua española:

La mayor parte de estos topónimos [os que están en territorios de fala hispana] presentan una única forma asentada; más raros, aunque no inexistentes, son aquellos con más de una variante ortográfica admitida: Cusco o Cuzco, Xiloá o Jiloá. ... presentan a veces términos con una morfología arcaica, como ... Ferreira (forma ant. de herrería) $)^{13}$, o conservan vestigios de antiguos usos ortográficos castellanos (Axarquía, Ayllón, Buyla, México u Ossa de Montiel) (RAE 2010: 640).

12 Artigo 10 da Lei 3/1983, do 15 de xuño, publicada no DOG do 14 de xullo de 1983.

13 Esta afirmación resulta equívoca: Ferreira, amais de ser forma galega (de FERRARIA, co feminino do sufixo -ĀRIUS > gal. - eiro, cast. - ero), pode ser tamén mozárabe, como o é o topónimo granadino Ferreira, con -ai- > -ei- "ora debida a la imela, ora más bien a la evolución natural del romance mozárabe semejante al del norte" (Menéndez Pidal 1986: 89), pero en ningún caso é equivalente de herreria, que porta a terminación - ería, formada polo anterior sufixo en combinación co gr. -i $\alpha$. Se o que se quere dicir é que o topónimo Ferreira tiña na súa orixe o significado 'ferrería', a expresión non é moi afortunada, dado que ao citar Ferreira como forma antiga do castelán herrería parece que se indica que esta é unha evolución daquela, cando se trata de linguas distintas (sexa mozárabe, galego ou portugués). 
Esa mesma comprensión con grafemas alleos ao actual sistema do español (como en Axarquía, Xiloá ou México) abondaría para admitir, por exemplo, todos os topónimos galegos que levan este grafema. Pero o que vale para as variantes do español non vale para outras linguas. Falando das formas "cooficiales", dise (o subliñado é meu):

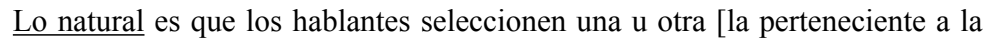
lengua española y otra propia de la lengua autonómica cooficial] en función de la lengua en la que están elaborando el discurso. En consecuencia, $\underline{\text { los }}$ hispanohablantes pueden emplear, siempre que exista, la forma española de esos nombres geográficos, y transferir aquellos topónimos que posean una expresión única, catalana, gallega o vasca: Pasó la mayor parte del verano en Sangenjo, pero tuvo tiempo para visitar Bilbao y llegar hasta Gerona; Su familia vive en Sant Feliu de Guixols (RAE 2010: 642).

É evidente que se esas formas existen hoxe é porque se forzou antinaturalmente desde o castelán (traducíndoas, semitraducíndoas, ou adaptándoas), non de maneira espontánea polos falantes ${ }^{14}$. Por outro lado, a aseveración sobre "o natural" é facilmente rebatible: cando un falante español utiliza topónimos franceses como poden ser Perpignan, Montpellier, Le Mans, Troyes, Vichy, Cannes, Orleans, ¿é natural que, por falar en español, se traduza ou se adapte fonética ou morfoloxicamente á forma española correspondente? E, de feito, non se fai así cos topónimos portugueses, moitos dos cales teñen a mesma morfoloxía ca os galegos (cf., entre moitos exemplos que se poderían apor, os portugueses Guarda, Ponte do Porto, Melides, Vila Nova, Barqueiro). ¿Nestes casos xa non é "natural”? Xa outras veces se ten posto de relevo a falsa inocencia deste adxectivo:

Con ese adxectivo natural inténtase ocultar ou, polo menos, disimular, non só os actos de planificación lingüística conscientes e dirixidos a uns determinados fins que están detrás do progreso do castelán como lingua nacional desde, polo menos, o século XIII, senón tamén o feito de que o poder económico, político ou militar supón que os estamentos que teñen ese poder poden permitirse o luxo de esixirlles ós demais que entendan e falen a súa variedade lingüística (Moreno Cabrera 2010: 66).

En principio, esta ideoloxía lingüística que se transloce nas publicacións da RAE non tería excesiva consecuencia práctica na nosa realidade porque todos os estamentos administrativos e mais os principais medios de comunicación en Galicia utilizan as

14 Outra cousa é o criterio de formación de exónimos, que existen en calquera lingua, e do que falaremos máis adiante. 
formas oficiais (os xornais galegos e El País, por exemplo ${ }^{15}$ ). Seguramente ten máis incidencia social o criterio adoptado pola Wikipedia en español, onde se recolle que se utilizará sempre o topónimo en castelán:

una mayoría de usuarios de la Wikipedia en español prefiere conservar el uso de los topónimos (exónimos) tradicionales en nuestra lengua. En todo caso, aludir a las leyes que regulan el uso de topónimos tampoco es un argumento válido, por cuanto lo hacen sólo en el ámbito de la correspondiente documentación y señalización oficial, no en el resto de los usos ${ }^{16}$.

¿"Só" no ámbito da documentación e a sinalización? Se engadimos a isto a cartografía e a maior parte da prensa, ¿que outros ámbitos de uso se poden indicar? En todo caso, para dar unha aparencia de obxectividade (dado que tal obxectividade está viciada desde o comezo), marcan unha prelación en que se citan fontes españolas cos topónimos castelanizados, e só en cuarto lugar, o topónimo oficial. A primeira delas é a devandita Ortografía da RAE (1999), onde, no “Apéndice 3” (pp.133-155) figura unha relación de topónimos entre os que se encontran *Puentes de $G^{a}$ Rodríguez, *Puebla del Caramiñal, *Puenteareas, *Puentedeume, *Villalba, *Villanueva de Arosa, *Vivero, *Órdenes, etc. Nesta obra, a documentación que "avala su empleo tradicional en castellano" dos municipios españois de máis de 10.000 habitantes está tirada das edicións de 1995 e 1998 da obra Entidades Locales en España, publicada polo MAP, “donde figura la relación oficial de tales entidades, con los nombres que estas han preferido registrar" (p. 133). Esta obra está claramente desfasada: o MAP non volveu reeditala, e non ten en conta a toponimia oficial, entre outras posibles razóns, porque, por exemplo, o nomenclátor de Galicia aínda non estaba rematado (foi publicado en 2003). Actualmente, para a elaboración da cartografía, o goberno español ten outros criterios. O Ministerio de Fomento, sen ir máis lonxe, réxese por unha lexislación máis recente: en concreto, no Real Decreto 1545/2007, de 23 de novembro, polo que se regula el Sistema Cartográfico Nacional (BOE n. 287, de 30 de novembro de 2007), estipúlase que ten como función a "recompilación, normalización e difusión da toponimia oficial' ${ }^{17}$.

15 Así se estipula no seu Libro de estilo: "Los nombres de poblaciones españolas deberán escribirse según la grafía aceptada oficialmente por el correspondiente Gobierno autónomo, que no siempre es la castellana. ... Las palabras escritas en un idioma distinto serán precedidas por el artículo que les correspondería en castellano, salvo que forme parte del nombre propio" (http://estudiantes.elpais.com/ libroestilo/apartado 08_052.htm).

16 En diante, as informacións da Wikipedia en español para os topónimos están tiradas de: http:// es.wikipedia.org/wiki/Wikipedia:Top $\% \mathrm{C} 3 \%$ B3nimos_de_Espa\%C3\%B1a.

$17 \mathrm{O}$ uso da cursiva é meu. Tirado de http://www.ign.es/ign/layoutIn/actividadesToponimia.do. 
Por tanto, recoller como bases principais fontes moi escoradas ideoloxicamente e só en cuarto lugar o criterio dos topónimos oficiais implica de maneira case sistemática a adopción das formas españolas como entrada principal para os topónimos galegos, o que parece ir en manifesta contradición cun dos cinco principios básicos da construción da Wikipedia: o punto de vista neutral.

Os dereitos da poboación castelanfalante, aos que invocan ás veces os defensores da toponimia castelanizada nas discusións, non se ven conculcados ao ofrecérense os topónimos na súa forma oficial. O Nomenclátor de Galicia tivo sempre un alto grao de aceptación social; a única contestación que houbo veu por parte dalgúns alcaldes que quixeron tirar réditos electorais avivando sentimentos localistas, con argumentos falaces, demagóxicos e politicamente irresponsables (os casos das Pobras -a do Caramiñal, de Trives e de Burón-, Vilalba, Ponteareas, A Coruña, San $\mathrm{Cibrao}^{18}$ ). Cando aqueles alcaldes deixaron de selo, os conflitos desapareceron (como se recoñece, por exemplo, en López Portas / Martínez Arribas 2002: 145), o cal tamén dá idea do efectiva que pode ser unha determinada política lingüística, sexa do signo que sexa. En Galicia, a maior parte da poboación castelanfalante utiliza os topónimos na súa forma propia, con poucas excepcións. Ademais, é unha obviedade que ninguén vai ser forzado a usar unha forma oral determinada, a non ser que estea obrigado por un uso oficial ou administrativo.

\subsection{O tratamento dos exónimos na ONU}

Por outro lado, esta política da naturalización dos topónimos choca frontalmente cos criterios da ONU para a formación de exónimos:

The United Nations Group of Experts on Geographical Names Glossary of Terms for the Standardization of Geographical Names defines an exonym as a name used in a specific language for a geographical feature situated outside the area where that language has official status (Helleland 2006: 127).

Así pois, para a ONU, os exemplos típicos de exónimos serían casos como Vienne (francés) e Vienna (inglés) para Wien en Austria. A ONU ten recoñecido repetidamente a importancia dos topónimos nas linguas minoritarias como parte integrante da herdanza lingüística de cada comunidade (resolución II/28, 1972), e recomenda o uso reducido dos exónimos en xeral, particularmente en cartografía, para facilitar a comunicación internacional (resolucións II/29 e IV/20). Os exónimos tradicionalmente recoñecidos, que teñen un gran peso cultural, son usualmente de

18 Pódense ver algúns detalles destes procesos en Boullón Agrelo 1992, Insua 2010. 
nomes de países ou ciudades moi importantes, ou con fondas connotacións relixiosas: Rome (inglés) por Roma (italiano) and Mecca (inglés), Meca (galego) por Makkah (árabe) (Kadmon 2006: 131). É evidente que non é esta a situación das ducias de topónimos galegos que aparecen deturpados nas fontes anteditas.

En consecuencia, sería desexable que a RAE se ativese ás recomendacións da ONU, e que as catro academias (vasca, catalá, galega e española) chegasen a un acordo para realizaren un tratamento da exonimia conxunto, non contraditorio e respectuoso coa realidade lingüística de cada lugar, que, no caso das linguas que teñen un territorio menor, se viu atacado tantas veces e desde tan antigo.

\section{Conclusión}

- Os topónimos con artigo presentan unha problemática específica con respecto á estandarización, pois ese artigo moderno pode ter outra orixe (neses casos adoita ser parte orixinaria dun substantivo hoxe opaco), e por tanto estar inmerso nun proceso non concluído de gramaticalización desa partícula. Ademais, existen vacilacións á hora de presentar na escrita as contraccións da lingua común coas preposicións correspondentes (en, con, de, fundamentalmente).

- A estandarización actual pode verse pexada por reminiscencias en certas institucións de políticas lingüísticas pretéritas, que tendían a traducir ao castelán de maneira case sistemática os nosos topónimos; ou, no caso de formas intraducibles, a castelanizar as características fonéticas e morfolóxicas da lingua galega. Se actualmente está estipulado pola lei que a única forma dos topónimos é a galega (e a forma oficial é a recoñecida polas institucións internacionais, como a ONU), novas realidades como o espazo internet veñen poñer en cuestión ese dereito: a Wikipedia non está nun territorio concreto, pero tense acceso a ela desde todos os territorios. A súa política lingüística segue a RAE, desbotando as formas oficiais e as recomendacións da ONU.

- Os criterios de creación de exónimos varían conforme pasa o tempo. Se na Idade Media era un recurso xeral, actualmente recoméndase a súa limitación de uso. E iso é así porque se recoñece o valor dos topónimos como parte da herdanza lingüística e cultural dun pobo, xunto co efecto positivo que pode ter a globalización ao permitir un mellor entendemento das culturas alleas. De calquera xeito, está claro que nunca se debería permitir o uso dun exónimo dentro do país que xerou o topónimo, ou, dito doutra maneira, un topónimo galego nunca pode ser tratado como exónimo en Galicia. 


\section{Fontes documentais históricas}

CasaAltamira = García, Oro, J. / Potela Silva, M J. (2003): La casa de Altamira durante el Renacimiento: estudio introductorio y colección diplomática (Santiago de Compostela: El Eco Franciscano).

CDBelvís = Rodríguez Núñez, C. C. (1989): "Santa María de Belvís, un convento mendicante femenino en la Baja Edad Media", Estudios Mindonienses 5, 335-485 = El monasterio de dominicas de Belvís de Santiago de Compostela (Ferrol).

CDGH = López Ferreiro, A. (1901): Colección diplomática de Galicia Histórica (Santiago de Compostela: Tipografía Galaica). [Ed. facsímil: Santiago de Compostela: Edicións do Cerne, 1998].

CDMaia = Maia, C. de Azevedo (1986): História do galego-portugués. Estado lingüístico da Galiza e do Noroeste de Portugal do século XII ao século XVI (com referência á situação do galego moderno) (Coimbra: I.N.I.C).

CDOseira = Romaní Martínez, M. (1989): La colección diplomática de santa María de Oseira (1025-1310). 2 vols. (Santiago de Compostela: Tórculo Edicións).

CDPombeiro = Lucas Álvarez, M. / Lucas Domínguez, P. P. (1996): El priorato benedictino de san Vicenzo de Pombeiro y su colección diplomática en la Alta Edad Media (Sada-A Coruña: Ed. do Castro).

CDSClodioRibeiro = Lucas Álvarez, M. / Lucas Domínguez, P. (1996): El monasterio de San Clodio do Ribeiro en la Edad Media: estudio y documentos (Sada / A Coruña: Edicións do Castro).

CDTui = Portela Silva, E. (1976): La región del obispado de Tuy en los siglos XII a XV. Una sociedad en expansión y en la crisis (Santiago: Tip. El Eco Franciscano). [Separata de Compostellanum (20)].

DipAstur = Floriano Cumbreño, A. C. (1949/1951): Diplomática española del período astur. Estudio de las fuentes documentales del reino de Asturias (718-910). 2 vols. (Oviedo: Diputación Provincial / Instituto de Estudios Asturianos).

Doc-1260 = Boullón Agrelo, A. I. / Monteagudo, H. (2009): De verbo a verbo: documentos en galego anteriores a 1260. Anexo 65 de Verba (Santiago de Compostela: Universidade de Santiago de Compostela) [Contén un anexo con 50 imaxes de documentos medievais].

DocHCoruña = González Garcés, M. (1988): Historia de La Coruña. Edad Media (A Coruña: Caixa Galicia). 
DocUnivSantiago = Lucas Álvarez, M. / Justo Martín, Ma X. (1991): Fontes documentais da Universidade de Santiago de Compostela. Pergameos da serie Bens do Arquivo Histórico Universitario (Anos 1237/1537). Edición diplomática (Santiago de Compostela: Consello da Cultura Galega).

DocXIII-XVI = Martínez Salazar, A. (1911): Documentos gallegos de los siglos XIII al XVI (A Coruña: Casa de la Misericordia).

García Conde, A. (1976): "Inventario de bienes de la mesa canonical de Lugo", BCPMHALugo 9, n. 85-86, pp. 307-320.

González González, J. (1944): Alfonso IX. 2 vols. (Madrid: Instituto Jerónimo Zurita).

LCPontevedra = Rodríguez González, Á. (1989): Livro do Concello de Pontevedra (1431-1463) (Pontevedra: Museo Provincial).

LCSantiago = Rodríguez González, Á (1992): Libro do Concello de Santiago (14161422) (Santiago de Compostela: Consello da Cultura Galega).

LTenzasSantiago = Méndez Fernández, M L L. (1991): Contribución ó estudio dun libro das Tenzas da Catedral de Santiago. Edición crítica e estudio dos folios I a 27. Memoria de Licenciatura. Universidade de Santiago de Compostela.

SAMI = López Ferreiro, A. (1899/1911): Historia de la Santa Apostólica Metropolitana Iglesia de Compostela. 11 vols. (Santiago de Compostela: Imprenta del Seminario). [Ed. facsímil: Santiago de Compostela: Sálvora, 1983].

TASantiago = Lucas Álvarez, M. (1997): La documentación del Tumbo A de la Catedral de Santiago de Compostela. Estudio y edición (León: Centro de Estudios e Investigación "San Isidoro") = Tumbo A de la Catedral de Santiago. Estudio y edición. Santiago de Compostela: Cabildo de la S.A.M.I. / Seminario de Estudios Galegos, 1998.

TBSantiago = González Balasch, Ma T. (2004): Tumbo B de la Catedral de Santiago (Santiago de Compostela: Cabildo de la S.A.M.I. Catedral / Seminario de Estudos Galegos).

TCaaveiro = Fernández de Viana y Vieites, J. I. / Pablos Ramírez, J. C. de / González Balasch, Ma T. (1996-1997): "El Tumbo de Caaveiro", Cátedra 3 (1996), 267437; 4 (1997), 221-385.

TCelanova $=$ Andrade Cernadas, J. M. (1995): O tombo de Celanova: estudio introductorio, edición e índices (ss. IX-XII) (Santiago de Compostela: Consello da Cultura Galega). 
TColoradoSantiago = Fernández Catón, J. Ma (1990): El llamado Tumbo Colorado y otros códices de la iglesia compostelana. Ensayo de reconstrucción (León: Centro de Estudios e Investigación "San Isidoro" (CSIC-CECEL) / Archivo Histórico Diocesano) = Archivos Leoneses 87/88 (1990), 7-292.

TSamos = Lucas Álvarez, M. (1986): El tumbo de san Julián de Samos (siglos VIII-XII). Estudio introductorio. Edición diplomática. Apéndices e índices (Santiago de Compostela: Publicacións de Caixa Galicia).

TToxosoutos = Pérez Rodríguez, F. (2004): Os documentos do tombo de Toxos Outos (Santiago de Compostela: Consello da Cultura Galega).

\section{Bibliografía citada}

Barreiro Fernández, J. R. (1986): Historia de la ciudad de La Coruña (A Coruña: La Voz de Galicia).

Bascuas, E. (2002): Estudios de hidronimia paleoeuropea gallega (Universidade de Santiago de Compostela: Santiago de Compostela).

Boullón Agrelo, A. I. (1991): “Ó redor do topónimo Pobra: Estado da cuestión e novos datos", Cadernos de Lingua 3, 15-24.

Búa Carballo, Carlos (2004): "Tres cuestións relacionadas coa toponimia antiga en -bris, moderna en -bre", en Boullón Agrelo, A. I. (ed.), Novi te ex nomine: estudos filolóxicos ofrecidos ao Prof. Dr. Dieter Kremer, [381]-399 ([A Coruña]: Fundación Pedro Barrié de la Maza).

Búa Carballo, Carlos (2007): “Topónimos galegos en -ollo de probable orixe prerromana", en Méndez, L. / Navaza, G. (eds.), Actas do I Congreso Internacional de Onomástica "Frei Martín Sarmiento". Santiago de Compostela, 2, 3 e 4 de setembro de 2002, 391-412 (Santiago de Compostela: Asociación Galega de Onomástica / Instituto da Lingua Galega).

Búa Carballo, J. C. / Lois Silva, S. (1994/95): "Los topónimos gallegos en -bre de origen prerromano", BNF 29/30, 13-41.

Cartografia de Galicia (séculos XVI ó XIX). Colección Puertas-Mosquera. Exposición, Colexio de Fonseca, abril de 2000. Texto e catalogación: Gonzalo Méndez Martínez. Universidade de Santiago de Compostela, 2000.

Cintra, L. / Cunha, C. (1984): Nova gramática do português contemporâneo (Lisboa: Edições Sá da Costa). 
Comisión de Toponimia da Xunta de Galicia (2003): Nomenclátor de Galicia. (Santiago de Compostela: Xunta de Galicia. Consellería da Presidencia). Dispoñible en: http://www.xunta.es/nomenclator/index.htm.

Estrela, E. / Pinto-Correia, J. D. (19994): Guia essencial da lingua portuguesa para a comunicação social (Lisboa: Notícias).

García Ares, Ma C. / Martínez Mayo, C. / Neira, N. (2002): "La estandarización de los topónimos gallegos: estado de la cuestión”, en Boullón Agrelo, A. I. (ed.), Actas do XX Congreso Internacional de Ciencias Onomásticas (Santiago de Compostela, 20-25 de setembro de 1999), 449-456. (A Coruña: Fundación Pedro Barrié de la Maza) [Ed. en CD-ROM].

Helleland, B. (2006): "The social and cultural values of geographical names", en Manual for the National Standardization of Geographical Names: United Nations Group of Experts on Geographical Names, 121-128 (New York: United Nations Publications).

HGNB = Piel, J. M. / Kremer, D. (1976): Hispano-gotisches Namenbuch (Heidelberg: Carl Winter).

Hoyo, J. del (1950?): Memorias del Arzobispado de Santiago. Edición preparada por Angel Rodríguez González e Benito Varela Jácome (Santiago de Compostela: Porto y Cía).

Insua, E. X. (2010): Orixe, peripecia e pertinencia do topónimo "San Cibrao" (Cervo) (Viveiro: Seminario de Estudos Terra de Viveiro).

Kadmon, N. (2006): "Exonyms, also called conventional names", en Manual for the National Standardization of Geographical Names: United Nations Group of Experts on Geographical Names, 129-131 (New York: United Nations Publications).

López Alsina, F. (1988): La ciudad de Santiago de Compostela en la Alta Edad Media (Santiago de Compostela: Ayuntamiento de Santiago de Compostela / Centro de Estudios Jacobeos / Museo Nacional de las Peregrinaciones).

López Portas, M. B. / Martínez Arribas, F. (2002): “A oficialidade das linguas en relación coa toponimia: o caso de 'A Coruña", Llengua i Dret 38, 117 148.

Lorenzo, R. (1975/1977): La traducción gallega de la Crónica General y de la Crónica de Castilla. Edición crítica anotada, con introdución, índice onomástico e glosario. 2 vols. (Ourense: Instituto de Estudios Orensanos "Padre Feijoo"). 
Madoz, Pascual (1845-1850): Diccionario geográfico-estadístico-histórico de España y sus posesiones de Ultramar (Madrid: Est. Literario Tipográfico de P. Madoz y L. Sagasti).

Martínez Lema, P. (2010): A toponimia das comarcas de Bergantiños, Fisterra, Soneira e Xallas na documentación do Tombo de Toxos Outos (séculos XII$X I V)$. Tese de doutoramento. Universidade de Santiago de Compostela.

Martínez Salazar, A. (1948) [1897-1898]: “Los nombres de La Coruña”, en Algunos temas gallegos. Vol. 1, 371-409 (A Coruña: RAG).

Mateus, M. H. Mira et al. (20035): Gramática da língua portuguesa (Lisboa: Caminho).

Méndez, L. (2002): "Questions about the use of articles with toponyms", en Boullón Agrelo, A. I. (ed.), Actas do XX Congreso Internacional de Ciencias Onomásticas (Santiago de Compostela, 20-25 de setembro de 1999), 503-512 (A Coruña: Fundación Pedro Barrié de la Maza) [Ed. en CD-ROM].

Menéndez Pidal, R. $\left(1986^{10}\right)$ : Orígenes del español. Estado lingüístico de la Península Ibérica hasta el S.XI (Madrid: Espasa-Calpe).

Miñano, S. (1826-1829): Diccionario geográfico y estadístico de España y Portugal. 11 vols.

Moralejo Álvarez, J. J. (2008): Callaica Nomina: estudios de onomástica gallega ([A Coruña]: Fundación Pedro Barrié de la Maza).

Moralejo Lasso, A. (1977): Toponimia gallega y leonesa (Santiago: Pico Sacro).

Moreno Cabrera, J. C. (2010): O nacionalismo lingüístico (Cangas do Morrazo [Pontevedra]: Morgante). [Orix. en español: Barcelona: Península, 2008].

Navaza, Gonzalo (2006): Fitotoponimia galega (A Coruña: Fundación Pedro Barrié de la Maza).

Navaza, Gonzalo (2007): Toponimia de Catoira (Catoira: Concello de Catoira).

Pensado, J. L. (1965): "Hidrotopónimo de origen lustral: 'Lavacolla"”, Archiv für das Studium der neueren Sprachen 202, 182-186.

RAG / ILG (2004 ${ }^{19}$ ): Normas ortográficas e morfolóxicas do idioma galego (Real Academia Galega / Instituto da Lingua Galega).

Real Academia Española (1999): Ortografía de la lengua española (Madrid: Espasa-Calpe). 
Real Academia Española / Asociación de Academias de la Lengua Española (2010): Ortografía de la lengua española (Madrid: Espasa-Calpe).

Rivas Quintas, Eligio (1982): Toponimia de Marín. Anexo 18 de Verba (Santiago: Universidade de Santiago de Compostela).

Rivas Quintas, E. (2007): "Fenomenoloxía toponímica de Galicia”, en Méndez, L. I Navaza, G. (eds.), Actas do I Congreso Internacional de Onomástica “Frei Martín Sarmiento". Santiago de Compostela, 2, 3 e 4 de setembro de 2002, 469-483 (Santiago de Compostela: Asociación Galega de Onomástica / Instituto da Lingua Galega).

Santamarina, A. (1988): "Efectos do contacto lingüístico na toponimia galega”, en Homenaxe a Joseph Piel, 87-96 (Tübingen: Niemeyer).

Solin, H. / Salomies, O. (1988): Repertorium nominum gentilium e cognominum latinorum (Hildesheim: Olms-Weidmann).

TopGal = Informe sobre o Nomenclátor e o Proxecto Toponimia de Galicia . Santiago de Compostela: Xunta de Galicia, 2005.

Vázquez Cuesta, P. / Luz, M. A. Mendes da (1980): Gramática da língua portuguesa (Lisboa: Ediçoes 70).

Vecindario de Ensenada 1759. Madrid: Centro de Gestión Catastral y Cooperación Tributaria, 1991.

\section{Recursos en internet}

AHUS = Base de datos dos fondos documentais Arquivo Histórico Universitario da Universidade de Santiago. Dispoñible en: http://www.usc.es/arquivo/fondos/ acceso.htm.

CODOLGA = Corpus Documentale Latinum Gallaeciae do Centro Ramón Piñeiro para a Investigación en Humanidades. Dispoñible en: http://corpus.cirp.es/ codolga/.

TMILG = Tesouro Medieval Informatizado da Lingua Galega do Instituto da Lingua Galega, dirixido por Xavier Varela. Dispoñible en: http://ilg.usc.es/tmilg. 